\title{
A formação comportamental de auditores contábeis independentes: um estudo multicaso
}

\author{
Luiz Alberton ${ }^{1} \&$ Ilse Maria Beuren ${ }^{2}$
}

\section{Considerações Iniciais}

As transformações ocorridas com a modernização dos processos produtivos, da abordagem de mercado e, principalmente, da forma de gerenciamento das pessoas, provocaram grandes alterações nas empresas. Tradicionalmente, os profissionais das empresas eram administrados por uma área que foi fortemente atingida por estas transformações através dos tempos, denominada recursos humanos.

Gil (2001) aponta cinco momentos marcantes da evolução da gestão de pessoas. O primeiro momento foi marcado pela administração científica, que teve como objetivo substituir a improvisação e o empirismo pelos fundamentos científicos às atividades administrativas. Em seguida veio a escola das relações humanas, que considerou os fatores psicológicos e sociais na produtividade. O terceiro momento teve como marco as relações industriais, em que as empresas foram forçadas, pelos movimentos sindicais, a se preocupar mais com as condições de trabalho e a concessão de benefícios a seus empregados. Já no quarto momento, surge a administração de recursos humanos, no qual entra em cena a abordagem sistêmica de administração. Por sua vez, o quinto momento é chamado de gestão de pessoas, marcado pela globalização da economia, evolução das comunicações, desenvolvimento tecnológico e competitividade, os quais forçam as empresas a passar por experiências como a reengenharia, terceirização e diminuição de tamanho, levando-as a novas concepções acerca das pessoas nas organizações.

Assim, as pessoas são consideradas o capital intelectual, que fornecem conhecimentos, habilidades, capacidades e inteligência, permitindo que decisões racionais sejam tomadas e os objetivos organizacionais sejam perseguidos. Então, o desafio nas organizações passa ser o gerenciamento de seus profissionais. A fim de vencer esta barreira, os profissionais ligados à área de gestão de pessoas devem trabalhar no desenvolvimento das competências e habilidades dos seus profissionais, visando prepará-las para as constantes mudanças do mercado de trabalho. Portando, o profissional de gestão de pessoas deve saber trabalhar com o elemento humano, com o seu desenvolvimento e, também, saber trabalhar por competência.

O desenvolvimento das organizações é fundamentado nas competências que seus profissionais possuem. Um profissional competente é aquele que consegue produzir resultados que tornam a organização mais competitiva, e, para isto, ele precisa desenvolver suas capacidades e habilidades técnicas e comportamentais. Assim, as organizações precisam capacitar seus profissionais, por meio do desenvolvimento de suas competências, para que se tornem mais produtivas e inovadoras, contribuindo com o desenvolvimento da organização.

Neste sentido, este artigo faz uma incursão nas teorias que abordam a gestão das pessoas nas organizações da atualidade. Além disso, apresenta um estudo multicaso, contendo as práticas de recrutamento e seleção, habilidades e competências requeridas das pessoas, capacitação de pessoas e avaliação de desempenho, especificamente relacionadas a pessoa do auditor. Ao final apresenta um modelo de formação comportamental de auditores contábeis independentes.

\footnotetext{
${ }^{1}$ Dr. Professor do Departamento de Ciências Contábeis. Universidade Federal de Santa Catarina

2 Dra. Professora do Programa de Pós-graduação em Administração - CPGA e do Depto. de Ciências Contábeis. Universidade Federal de Santa Catarina
} 


\section{Fundamentação Teórica}

Neste tópico, discorre-se sobre as competências requeridas na gestão de pessoas em organizações. Em seguida são abordados os fundamentos teóricos sobre recrutamento, seleção, capacitação, avaliação de desempenho de pessoas e as teorias comportamentais.

\section{Competências}

Fala-se muito em competências e na necessidade de identificar as competências que a empresa precisa. Segundo Figueiredo (2001), algumas são intrínsecas ao ser humano, ele traz consigo ao nascer. Muitas delas ele adquire depois, por meio da aquisição do conhecimento. As competências adquiridas pelo conhecimento são as gerenciais e as técnicas. A competência técnica refere-se à capacidade de realizar determinadas especialidades. Já a competência gerencial relaciona-se à capacidade de solucionar problemas e de saber relacionar-se com as outras pessoas.

Em função das competências técnicas e gerenciais identificadas, o profissional de gestão de pessoas procurará colocar as pessoas certas nos cargos vagos nas organizações, porque a principal função do profissional da área de gestão de pessoas é identificar, dentro da organização, quais as competências essenciais e necessárias para o sucesso do negócio.

Competência, conforme Wood Jr. e Picarelli Filho (1999:126), é um conjunto integrado de conhecimentos, habilidades e atitudes, e "significa conhecimento aplicado e orientado para melhorar o desempenho do indivíduo, do grupo e da organização".

França e Motta (2001) definem competência como sendo a quantidade que uma pessoa coloca de talentos, habilidades e experiências para alcançar seus próprios objetivos e os da empresa.

Wood Jr. e Picarelli Filho (1999) apresentam as seguintes competências:

a) de negócios, que envolve a compreensão do negócio, do setor de atividades, análise de custo-benefício, domínio do conhecimento do campo do comportamento organizacional, domínio da teoria e técnicas de gestão de mudanças e domínio de técnicas de gestão de projetos;

b) interpessoais, envolve coaching, feedback, condução de grupos, negociação, apresentação, preparação de relatórios.

c) intelectuais, envolve síntese de informações, auto-aprendizado e formulação de estratégias de atuação.

d) gerenciais, que envolve competências interacionais com líderes, pares e liderados; de solucionar problemas; de capacitação, que envolve tanto a orientação para a ação como a flexibilidade e a adaptação às mudanças; e de comunicação oral, escrita e a interação com outras culturas, ou seja, saber comunicar idéias e saber compreender as outras pessoas.

Kanaane (1999) cita competências no campo profissional, tais como, capacidade em estabelecer redes de trabalho, concentração criativa, capacidade conceitual, domínio de línguas estrangeiras, multifuncionalidade, versatilidade, visão de conjunto de longo prazo, capacidade de mudar, lidar com pressão, ambigüidades, incertezas, de utilizar os conhecimentos acumulados, de implementar e de ter equilíbrio da vida pessoal com a profissional.

Essas competências enumeradas são necessárias ao efetivo desempenho profissional. Portanto, os caçadores de talentos, de acordo com Figueiredo (2001), precisam saber o que deve ser buscado e observado nos candidatos a preencher uma vaga. Devem buscar o equilíbrio entre o Quociente de Inteligência - QI e o Quociente Emocional - QE no candidato, ou seja, entre a razão e a emoção.

Goleman (1995:46), explica que "o QI contribui com cerca de 20 por cento para os fatores que determinam o sucesso na vida, o que deixa os 80 por cento restantes por 
conta de outras variáveis". Estas outras variáveis podem ser a variação da classe social, pura sorte, e outras características que o ser humano traz para a vida. Dentre essas outras características que o autor cita, encontram-se as seguintes aptidões:

a) capacidade de criar motivações para si próprio e de persistir num objetivo apesar dos percalços;

b) capacidade de controlar impulsos e saber aguardar pela satisfação de seus desejos;

c) capacidade de se manter em bom estado de espírito e de impedir que a ansiedade interfira na capacidade de raciocinar; e

d) capacidade de ser empático e autoconfiante.

No momento atual, as pessoas devem saber como trabalhar com a razão, a emoção e com as duas juntas. Porém, de acordo com Bassanesi e Zanuzzi (2000:32), está surgindo uma nova teoria sobre a inteligência, desenvolvida por Robert Sternberg, da Universidade de Yale, nos Estados Unidos da América, que se diferencia das teorias de inteligência múltiplas de Howard Gardner e da inteligência emocional apresentada por Daniel Goleman. Tal teoria busca encontrar explicações para a seguinte pergunta: "Como pessoas que vão mal na escola conseguem ter sucesso na vida e, da mesma forma, por que indivíduos brilhantes na vida escolar conseguem se dar mal - ou ter um desempenho apenas medíocre - profissionalmente e no dia-a-dia?". Estas respostas Sternberg procura responder por meio do desenvolvimento da teoria da inteligência prática.

Essa nova teoria que está emergindo ainda está em fase de preparação e está sendo testada pela Universidade de Michigan Business Scholl - UMBS para selecionar candidatos ao curso de MBA (Master in Business Administration). O teste de seleção procura medir a capacidade de aquisição de conhecimento tácito (oculto, secreto, etc.) dos candidatos e revelar aqueles que têm habilidades para adaptar o que aprendem às situações práticas do dia-a-dia.

Assim, as teorias que procuram identificar o nível de QI e QE, bem como esta nova teoria que está se propondo encontrar o quociente prático dos candidatos, podem ajudar os profissionais de gestão de pessoas buscar as competências humanas necessárias no candidato ao preenchimento de um cargo vago da empresa.

\section{Cargos}

O trabalho dos caçadores de talentos para as empresas consiste em buscar profissionais com competências para ocupar cargos diferentes. Mas, primeiramente, deverá definir quais os cargos necessários à organização, para, então, colocar as pessoas certas nesses cargos vagos.

Todas as organizações, sejam elas de pequeno, médio ou grande porte, necessitam criar cargos em suas estruturas organizacionais, para poder contratar e gerir seu pessoal. Gerenciar os cargos na organização implica resolver problemas que aparecem, em função das necessidades da empresa e das novas realidades do mercado. Tais problemas, conforme Carvalho e Nascimento (2000), estão relacionados com a diminuição da produção e da qualidade, desmotivação na ocupação dos cargos atuais, reclamações trabalhistas, manifestações, etc. Além disso, para acompanhar o avanço tecnológico, torna-se necessário planejar e replanejar, periodicamente, os cargos, bem como suas remunerações.

Para manter os cargos atualizados é necessário analisá-los. Analisar cargos, de acordo com Robbins (1999:348), "implica desenvolver uma descrição detalhada das tarefas envolvidas num cargo, determinando a relação de um dado cargo com outros cargos e averiguando o conhecimento, habilidades e capacidades necessários para um empregado se desempenhar com sucesso no cargo".

Carvalho e Nascimento (2001:26) ressaltam que os cargos de uma organização devem conter as titulações. A titulação é a "identificação atribuída a um conjunto de 
funções, evidenciando a principal, de modo a diferenciá-la das demais existentes na estrutura". A diferenciação é feita com base no nível funcional e/ou atividade específica, na estrutura organizacional e na área ou atividade.

A nomenclatura do cargo pode conter prefixo, infixo e sufixo, assim como a palavra. O prefixo determina a nomenclatura referente ao nível funcional e/ou atividade específica (Diretor/Sócio, Gerente, Supervisor, Assistente, Auxiliar). O infixo determina a nomenclatura referente à linha estrutural (Diretoria, Departamento, Seção). O sufixo determina a nomenclatura referente à atividade preponderante onde está alocado o cargo (Recursos Humanos, Auditoria, Treinamento, Patrimônio). Conhecida a estrutura organizacional e definidos os cargos que serão ocupados, inicia-se o processo de recrutamento dos profissionais.

É por meio da estrutura de cargos que o candidato a uma vaga conhece a estrutura salarial e ocupacional da entidade. De posse da estrutura de cargos e sua remuneração, o recrutador tem condições de iniciar o processo de recrutamento dos profissionais.

\section{Abordagens e práticas de recrutamento}

O recrutamento é uma das etapas mais importantes do processo de admissão de um novo profissional. Por isso muitas empresas pesquisam primeiramente em seu ambiente interno, para depois ir ao mercado de trabalho. Este pode ser a própria comunidade onde a empresa atua, ou no âmbito regional, nacional e internacional, dependendo das necessidades de preenchimento de determinados cargos.

Para Chiavenato (1999:92), a eficácia no recrutamento está na atração de candidatos suficientes para suprir o processo de seleção. Conceitua recrutamento como "um conjunto de técnicas e procedimentos que visa atrair candidatos potencialmente qualificados e capazes de ocupar cargos dentro da organização. É basicamente um sistema de informação, através do qual a organização divulga e oferece ao mercado de recursos humanos as oportunidades de emprego que pretende preencher".

De acordo com Carvalho e Nascimento (2000), uma das contribuições decisivas para que a empresa produza bens e serviços com produtividade e qualidade é fruto de uma força de trabalho bem recrutada. $O$ elo de ligação entre a empresa e o mercado de trabalho é o processo de recrutamento. A identificação do perfil de recursos humanos, necessários à organização, fornece uma visão clara do número e do tipo de profissionais (competências) necessários para o seu pleno funcionamento em um determinado período.

Com a identificação pronta, a empresa efetua o levantamento das reais necessidades e inicia o processo de recrutamento. O processo de recrutamento, que visa aumentar ou suprir a necessidade de pessoal, pode ser realizado por meio de recrutamento interno ou externo.

O recrutamento interno fundamenta-se no remanejamento ou movimentação de pessoas da própria organização, recrutamento este que objetiva promover os colaboradores, atender programas de desenvolvimento e planos de carreira funcional. Segundo Hindle (1999), buscar candidatos dentro da empresa é mais fácil, pois eles já conhecem a empresa e a sua cultura.

Por sua vez, o recrutamento externo, de um novo profissional, pode ser realizado por vários meios. Tais meios são apontados por Carvalho e Nascimento (2000) como anúncios na imprensa, escolas e universidades, associações de classes, recomendações, agências de emprego, arquivos de candidatos que se apresentaram à empresa anteriormente, apresentação espontânea do candidato e intercâmbio de empresas. Outros meios que auxiliam no recrutamento externo são os anúncios em periódicos da empresa e em páginas de divulgação de vagas na internet.

\section{Abordagens e práticas de seleção}

Após o recrutamento a empresa irá selecionar, dentre aqueles que se 
apresentaram para o preenchimento da vaga, qual deles melhor atende as expectativas previstas na descrição e especificação do cargo. A seleção de pessoas, de acordo com Carvalho e Nascimento, (2000: 114), "tem a finalidade de escolher entre os candidatos recrutados, aqueles que se revelarem mais qualificados na triagem inicial do recrutamento".

O objetivo da seleção, de acordo com Robbins (1999), "é combinar características individuais (capacidades, experiência e outros) com os requisitos do cargo".

Para Almeida (1996:410), o processo de seleção "representa a atividade de escolher os melhores candidatos, com base nos parâmetros previamente estabelecidos por ocasião do recrutamento". Normalmente, segundo Robbins (1999), Chiavenato (1999), Green (2000), Carvalho e Nascimento (2000) e Gil (2001), o processo de seleção nas empresas envolve as fases de análise de currículo; testes de conhecimento; testes psicológicos; testes de personalidade; análise de grafologia; entrevista de seleção; e dinâmica de grupo.

\section{Análise de currículos}

Um dos meios utilizados no processo de seleção é a análise do currículo do candidato. O currículo do candidato traz informações úteis ao processo, porém não dá uma visão real do candidato. Pela análise do currículo, conforme Gil (2001), pode-se identificar sinais de competência profissional, experiências práticas, adequação ao cargo, tendência do candidato permanecer no cargo e de seguir carreira, vontade de trabalhar e de aceitar novos desafios.

No entanto, Hindle (1999) cita que o currículo pode evidenciar tentativas do candidato em forjar ou esconder determinadas informações. Recomenda que 0 selecionador procure lapsos na cronologia do currículo, verifique qualificações com as instituições pertinentes, faça estimativa do tempo médio de permanência em cada lugar e avalie se o estilo do currículo indica um candidato bem organizado.

Segundo Bernardi (1998), algumas empresas já estão adotando, como fator de eliminação de candidatos na análise do currículo, o conceito que o curso de graduação da universidade onde o candidato se formou possui.

Os candidatos que conseguirem passar pela análise do currículo serão submetidos a testes de conhecimentos.

\section{Testes de conhecimento}

Os testes de conhecimento têm como finalidade medir o grau de conhecimentos e habilidades que o candidato possui sobre determinados assuntos. Para Carvalho e Nascimento (2000:120), "a medição desses conhecimentos representa uma significativa cooperação para se decidir a conveniência ou não de se admitir o candidato e para determinar a classe e a intensidade do treinamento exigido para o caso". Esses testes podem ser escritos, orais e práticos ou simuladores de desempenho.

Os testes empregados nos processos seletivos estão voltados à verificação, tanto dos aspectos técnicos do candidato, como dos comportamentais. Outra fase do processo de seleção, além dos testes de conhecimento, é a realização dos testes que dizem respeito ao estado psicológico do candidato.

\section{Testes psicológicos}

Os testes psicológicos dão possibilidade de o selecionador avaliar o potencial intelectual e dos traços de personalidade do candidato. A prática do uso dos testes psicológicos na seleção de pessoas tornou-se comum em grandes empresas e demonstrou ser um importante meio de decidir quem selecionar.

Os tipos de testes psicológicos mais utilizados são os testes de aptidões. Os testes de aptidões medem capacidades como leitura, escrita, clareza verbal e habilidade de lidar 
com números. Para Carvalho e Nascimento (2000:126), "pode-se caracterizar a aptidão como sendo uma disposição natural do indivíduo voltada para uma determinada atividade". A aptidão é uma manifestação individual inata ao ser humano, que existe independentemente da aprendizagem e do treinamento. No entanto, a aptidão pode ser desenvolvida por meio do treinamento, e, quando isto acontece, aparece a capacidade. A capacidade é um exercício de melhoria da aptidão, e "quanto maior for a capacidade do indivíduo, tanto mais aperfeiçoada é a sua técnica de usar a aptidão que possui".

Geralmente, as empresas se utilizam, para selecionar profissionais para determinados cargos, de testes de aptidões mentais. Esses testes também são conhecidos por aptidões intelectuais, são empregados na seleção de pessoas em cargos que se exige tomadas de decisões, raciocínios e outras atividades intelectuais ou cognitivas.

Os testes de aptidões são essenciais no processo de seleção de auditores, porém, de nada adianta o novo auditor ter um bom currículo e ter passado nesses testes, se não possui um determinado padrão de comportamento e de motivação, e, no primeiro contato com os clientes, estragar uma transação de longos anos. Assim, é necessário que o candidato realize testes de personalidade.

\section{Testes de personalidade}

Os testes abordados objetivam identificar o que o candidato é capaz de fazer, mas não possibilitam avaliar se realmente ele vai fazer. Os testes de personalidade normalmente englobam provas verbais, visuais e escritas. Hindle (1999:49) cita que os testes de personalidade "partem do princípio de que características pessoais são mensuráveis. A presença ou ausência de certos traços corresponderia a sucesso no local de trabalho e, assim, adequação ao cargo".

Os testes de personalidade ajudam a identificar características importantes dos candidatos, que podem influenciar no sucesso da ocupação do cargo. Além dessas baterias de testes, também os candidatos são submetidos, em algumas empresas, à análise da grafologia.

\section{Análise da grafologia}

Grandes empresas utilizam-se, no processo de seleção, dos testes de grafologia para interpretar as características reveladas pela caligrafia do candidato. No Dicionário Aurélio Eletrônico (1999) encontra-se a seguinte definição da grafologia: "análise da personalidade de um indivíduo por meio do estudo dos traços de sua escrita, como, p. ex., o tamanho das letras, o ângulo de inclinação, a regularidade, a rapidez e a espessura do traçado". De acordo com Hindle (1999), o ritmo regular das letras indica coerência, letras $\mathrm{T}$ eretas revelam entusiasmo, rabiscos iniciais sugerem dependência, arcos nas letras sugerem diplomacia, etc.

Figueiredo (1999:55) cita que, "por meio da grafologia, será possível ter uma análise quanto às tendências do profissional avaliado, como relacionamento interpessoal; agressividade; capacidade de assimilar mudanças, tão comuns na empresa atual; produtividade, outra palavra em moda nos dias atuais; dinamismo, participação e cooperação".

Realizadas essas baterias de testes, o candidato passa para a fase seguinte, isto é, pelo processo de entrevista.

\section{Entrevista de seleção}

O processo de selecionar profissionais é complexo e muitas vezes demorado, requerendo reflexão e planejamento. O selecionador, ao terminar os testes abordados anteriormente, buscará obter outras informações por meio da entrevista de seleção.

O objetivo principal da entrevista de seleção é obter do candidato informações não 
reveladas durante as fases de testes. A entrevista possibilita conhecer melhor o candidato para tomar a decisão de contratá-lo ou não. Ela é uma complementação dos testes e, ao mesmo tempo, é uma forma de integração do candidato aprovado com a empresa.

A entrevista de seleção é o método mais direto para avaliar a aparência, postura e modo de expressão do candidato. Também é um método direto para medir a rapidez de reação nas respostas, a qualidade da expressão verbal e as reações do candidato a determinadas perguntas.

Um dos aspectos importantes do processo de seleção, além de o entrevistador apresentar todas as vantagens e oportunidades que o emprego oferece ao entrevistado, é informar também os pontos difíceis ou atividades ruins que o cargo possui.

As dificuldades e problemas encontrados nos colaboradores, de acordo com Krausz (2001), quando analisados com atenção, encontram suas raízes nas falhas de contratação. Todo trabalhador, qualquer que seja seu campo de atuação, dispõe de um capital humano para investir numa determinada atividade, seja ela autônoma, liberal ou com vínculo empregatício.

Portanto, tendo esclarecido os pontos bons e os ruins do cargo, o candidato não correrá o risco de, no futuro, se for contratado, desmotivar-se com seu emprego ao desempenhar atividades difíceis ou rotineiras.

Algumas empresas também adotam a dinâmica de grupo como uma das fases do processo de seleção.

\section{Dinâmica de grupo}

Gil (2001) aborda também, como prática de seleção, o emprego da dinâmica de grupo após os candidatos terem passado pelas outras técnicas de seleção. A dinâmica de grupo consiste em avaliar como os candidatos se comportam mediante situações criadas pelos avaliadores. Esta técnica mostra-se bastante adequada para avaliar no candidato características, como a liderança, sociabilidade, iniciativa, comunicabilidade, criatividade, espontaneidade, capacidade de análise, capacidade de julgamento, capacidade de argumentação, capacidade de atuar sob pressão, controle das tensões e da ansiedade, tomada de decisões, e habilidade para lidar com situações de conflito.

Além dessas técnicas utilizadas pela psicologia organizacional, segundo Figueiredo (1999), outros mecanismos menos convencionais, mas que também têm seu valor, como o mapa astral e a numerologia, são utilizados nos processos de seleção.

Identificadas as técnicas do processo de seleção adotadas nas empresas em geral, é fundamental verificar qual o processo adotado para a capacitação de pessoas.

\section{Abordagens e práticas de capacitação de pessoas}

Diversos termos são encontrados na literatura para denominar atividades relacionadas a capacitação de pessoas: treinamento, educação continuada, capacitação, aperfeiçoamento, formação e desenvolvimento.

Além desses termos utilizados nas empresas para capacitar seus profissionais, de acordo com Gil (2001:123), atualmente as organizações estão utilizando também a educação corporativa, "que compreende todas as atividades realizadas para identificar, modelar, difundir e aperfeiçoar as competências essenciais para o sucesso de uma organização".

Ainda, de acordo com Gil (2001:121), o treinamento no enfoque tradicional "é o meio para adequar cada pessoa a seu cargo, com vista no alcance dos objetivos da organização". Porém, no enfoque de gestão de pessoas, o treinamento representa muito pouco, é preciso capacitar as pessoas, ou seja, "o que se necessita é de processos capazes de desenvolver competências nas pessoas, para que se tornem mais produtivas e inovadoras para contribuir com a organização". Desenvolver pessoas significa fornecerIhes a formação necessária para modificar antigos hábitos, desenvolver novas atitudes e 
para que eles se capacitem para aprimorar seus conhecimentos. A capacitação de pessoas transcende o treinamento e se aproxima do processo de educação. Apesar do autor enfatizar a importância de usar os termos capacitação e educação, em sua abordagem utiliza o termo treinamento para capacitar pessoas.

Para Robbins (1999), os treinamentos objetivam modificar uma ou mais habilidades. As habilidades são classificadas em: capacidade de leitura e escrita, técnica, interpessoal e solução de problemas.

Algumas organizações, atualmente, estão fornecendo apoio e recursos necessários ao desenvolvimento da carreira do profissional, e estão colocando a este profissional, a responsabilidade pelo seu desenvolvimento. Green (2000:126) menciona que as empresas tem programas de carreira auto-dirigidos que "enfatizam o papel do indivíduo no desenvolvimento de habilidades que serão necessárias pela organização no futuro". A empresa transfere a responsabilidade pelo desenvolvimento às pessoas e assume a responsabilidade pelo desenvolvimento de sistemas de informação que auxiliam os indivíduos.

Assim, o processo de desenvolvimento nessas empresas deixa de ser um direito e passa ser uma responsabilidade do empregado. $O$ trabalhador além de desenvolver suas atividades e buscar novos conhecimentos, passa também a ser um instrutor (coach) de outras pessoas. O termo coach, segundo Gil (2001:282), "tem origem no campo esportivo e tem sido utilizado para designar o papel do técnico, aquele profissional que treina times de futebol ou basquete". Esse termo passou a ser utilizado dentro das organizações não para designar um cargo, mas um papel profissional: "o da pessoa que se compromete a apoiar alguém com vista em melhorar seu desempenho e promover seu desenvolvimento profissional e pessoal".

O papel do coach é de um profissional que, além de se comprometer com o resultado, é responsável pelo próprio desenvolvimento e realização da pessoa que é designada como seu cliente.

Gil (2001:283) explica que a ação do coach é o coaching: "processo desenvolvido com as pessoas (ou clientes)". As finalidades do coaching são as seguintes:

a) auxiliar a descobrir o potencial de trabalho;

b) ajudar na percepção das oportunidades e se libertar de limites;

c) fornecer suporte para assumir o gerenciamento do próprio medo, questionando premissas e paradigmas;

d) auxiliar na definição de objetivos e estabelecimento de metas e assegurar que estejam na direção certa;

e) apoiar a descoberta das competências necessárias para o melhor desempenho e sua avaliação;

f) ajudar na superação de obstáculos como crenças, atitudes e condutas que dificultam a realização profissional;

g) desenvolver um sistema de referência para dar e receber feedback para motivação e melhoria de desempenho;

h) fornecer suporte e estrutura para melhorar a comunicação com a equipe e gerenciamento de conflitos;

i) auxiliar na percepção das deficiências profissionais do indivíduo;

j) ajudar na correção da conduta no trabalho;

k) encorajar o crescimento profissional e pessoal.

Assim, um coach pode estar auxiliando no desenvolvimento de lideranças, no discurso, na construção da segurança pessoal, na etiqueta profissional, na lapidação da personalidade, nas relações públicas e interpessoais, no gerenciamento de conflitos e na construção da carreira profissional. 
O coaching apresenta algumas diferenças com os outros processos desenvolvidos dentro e fora das empresas. A Figura 1 apresenta as diferenças entre o coaching e a psicoterapia, coaching e aconselhamento, coaching e treinamento.

\begin{tabular}{|c|c|}
\hline COACHING & PSICOTERAPIA \\
\hline $\begin{array}{l}\text { Voltado para o desempenho } \\
\text { profissional }\end{array}$ & $\begin{array}{l}\text { Enfoca fundamentalmente o indivíduo e seus } \\
\text { problemas pessoais }\end{array}$ \\
\hline Énfase no futuro & Énfase muito no passado \\
\hline Rápido e superficial & Longa e profunda \\
\hline $\begin{array}{l}\text { Preocupa-se com o que está } \\
\text { faltando }\end{array}$ & Preocupa-se com o que está \\
\hline Visa à ação & Visa modificações na personalidade \\
\hline COACHING & ACONSELHAMENTO \\
\hline Destina-se a qualquer empregado & Destina-se a empregados que tem problemas \\
\hline Menos direto & $\begin{array}{l}\text { Mais direto, procura chamar a atenção do } \\
\text { empregado para o problema }\end{array}$ \\
\hline $\begin{array}{l}\text { Fornece elementos para que o } \\
\text { cliente decida se convém mudar }\end{array}$ & $\begin{array}{l}\text { Procura fazer com que o empregado reconheça } \\
\text { a necessidade de mudar }\end{array}$ \\
\hline $\begin{array}{l}\text { Procura-se conhecer alternativas } \\
\text { possíveis para melhorar o } \\
\text { desempenho }\end{array}$ & $\begin{array}{l}\text { Procura-se identificar a causa do problema e } \\
\text { reforçar o comportamento correto }\end{array}$ \\
\hline COACHING & TREINAMENTO \\
\hline$\vec{E}$ individual & Direcionado normalmente a grupos \\
\hline $\begin{array}{l}\text { Os objetivos são definidos ao } \\
\text { longo do processo e exige } \\
\text { relacionamento muito franco e } \\
\text { intenso do que no treinamento }\end{array}$ & Trabalha com objetivos definidos e operacionais \\
\hline
\end{tabular}

Figura 1 - Diferenças do coaching com a psicoterapia, aconselhamento e treinamento

Fonte: adaptado de Gil (2001).

Por sua vez, o mentoring é muito semelhante ao coaching e sua aplicação é restrita aos empregados que possuem muito potencial e busca tornar o cliente um aliado da empresa. O Mentoring procura enfatizar os valores e a estrutura política da empresa, o estabelecimento de contatos e o acesso aos recursos necessários. O mentor precisa ser escolhido entre as pessoas capazes de representar os valores da organização e com autoridade suficiente para proporcionar os meios para que o desempenho de seus clientes atinja o nível pretendido.

\section{Abordagens e práticas de avaliação de desempenho}

$\mathrm{Na}$ atualidade é dada bastante ênfase à avaliação de desempenho. De acordo com Robbins (1999), serve para compensar funcionários, passar feedback de desempenho, identificar necessidades de treinamento, promover pessoas, planejar a gestão de pessoas, reter ou dispensar pessoas.

Gil (2001) destaca a importância da avaliação de desempenho como um meio de desenvolver as pessoas da organização nos seguintes itens:

a) serve para definir o grau de contribuição que cada pessoa dá para a organização;

b) possibilita identificar as pessoas com qualificação superior à requerida pelo cargo;

c) ajuda identificar se os programas de treinamento têm contribuído para a melhoria do desempenho; 
d) contribui para o auto-conhecimento e auto-desenvolvimento das pessoas;

e) serve para definir o perfil requerido dos ocupantes dos cargos;

f) serve como subsídios para remunerar e promover pessoas;

g) contribui para elaborar planos de ação para desempenhos insatisfatórios.

Essas são algumas das contribuições da avaliação de desempenho individual para a melhoria do desempenho organizacional. Para Robbins (1999), normalmente, a avaliação visa identificar os resultados de tarefas individuais, os comportamentos e os traços (ter boa atitude, mostrar confiança, cooperação e outros) das pessoas, e podem ser avaliadas pelo superior imediato, pelos colegas, auto-avaliação, por subordinados imediatos, utilizando-se de abordagem total ou avaliação de 360 graus.

Outro ponto que está em voga no ambiente empresarial é a capacitação dos profissionais nas habilidades e competências comportamentais.

\section{Teorias comportamentais}

Os estudos das teorias comportamentais têm procurado conhecer como a pessoa em qualquer contexto realiza determinada ação. O comportamento é conceituado por Kanaane (1999:80) como "um conjunto de operações materiais e simbólicas, entendido como um processo dialético e significativo em permanente interação. $O$ aspecto dialético do comportamento possibilita-nos compreendê-lo como um sistema de múltiplas interações".

Compreender as pessoas sempre foi uma tarefa difícil, e, partindo desta premissa, precisam ser analisadas atitudes como habilidades, liderança, sociabilidade, experiência de vida, histórico sócio-econômico e satisfação com a vida. Para Kanaane (1999), deve ser considerada a existência de diferentes concepções do comportamento, tais como o comportamento individual (retrata as reações inerentes à pessoa e suas condutas no contexto organizacional), o comportamento grupal (diz respeito à soma de reações dos membros que compõem um grupo) e comportamento organizacional (são as manifestações emergentes no contexto das organizações, indicando os controles, o processo decisório e os esquemas técnico-administrativos assumidos num dado momento organizacional). Assim, o comportamento é oriundo de ações e reações que foram estimuladas no meio ambiente e que atuam no indivíduo, grupos e na organização.

Robbins (1999) aponta três momentos que marcaram a evolução histórica do comportamento organizacional. $\mathrm{O}$ primeiro, chamado de Práticas Iniciais, teve a contribuição de Adam Smith, Charles Babbage e Robert Owen com suas idéias que influenciaram na concepção da direção e das fronteiras do comportamento organizacional. O segundo momento foi marcado pela Era Clássica da Administração, na qual as primeiras teorias da administração começaram a evoluir, surgindo a Administração Científica criada por Frederick Taylor, Henri Fayol, Max Weber, Mary Parker Follett e Chester Barnard. O terceiro momento, chamado de Era Comportamental, foi marcado pelo reconhecimento do lado humano das organizações e pela pesquisa sobre a ciência comportamental realizada nas organizações.

Também, o mesmo autor explica que precisam ser estudadas outras disciplinas comportamentais para entender o comportamento organizacional, as quais são as seguintes:

a) a Psicologia contribui para a aprendizagem, motivação, personalidade, percepção, treinamento, eficácia da liderança, satisfação no trabalho, tomada de decisão individual, avaliação de desempenho, mensuração de atitude, seleção de empregados, dimensionamento do trabalho e estresse no trabalho;

b) a Sociologia estuda as pessoas em relação aos seus colegas e contribui para: dinâmica de grupo, equipes de trabalho, comunicação, poder, conflito, comportamento intergrupal, teoria da organização formal, tecnologia organizacional e cultura organizacional; 
c) a Psicologia Social concentra-se na influência que as pessoas exercem umas sobre as outras. Contribui para a mudança comportamental, de atitudes, comunicação, processos de grupo e tomada de decisão em grupo;

d) a Antropologia ajuda no entendimento dos estudos de valores comparativos, atitudes comparativas, cultura organizacional, ambiente organizacional e análise de cruzamento das culturas;

e) a Ciência Política estuda o comportamento de indivíduos e grupos em relação aos conflitos, alocação de poder, e como as pessoas manipulam o poder em detrimento de interesses individuais.

Atualmente, nas organizações, o maior obstáculo encontrado é a ineficiência e a inadequada competência comportamental das pessoas. Assim, para dar suporte ao modelo de formação de auditores contábeis independentes, foram abordadas as teorias de liderança, de motivação, de comunicação, de análise transacional, de programação neurolingüística, de aprendizagem, de comportamento individual (habilidades, personalidade, percepção), de tomada de decisão, de criatividade, de ética no trabalho, de administração do estresse, de equipes de trabalho, de conflito e de negociação.

a) Liderança

O objetivo de trabalhar este tópico é identificar na literatura como a liderança é tratada nas organizações e quais são suas teorias. As principais abordagens sobre liderança são as teorias dos traços, teorias comportamentais, teorias contingenciais e as novas teorias de liderança. Nas teorias comportamentais são encontrados os estudos de Ohio, Michigan, Escandinavos e a teoria da Grade Gerencial. Nas teorias contingenciais encontram-se os modelos de Fiedler, a Teoria da Liderança Situacional e a Teoria do Caminho-Objetivo/Meta. Por sua vez, as teorias mais recentes, ou novas, de liderança, abordam a Teoria da Atribuição de Liderança, da Liderança Carismática, da transformacional versus a Liderança Visionária e a liderança de equipes.

b) Motivação

O estudo da motivação procura responder questionamentos sobre a natureza humana nos processos organizacionais. Todo comportamento humano tem um motivo, uma causa, uma coerência interna. A motivação é individual e de acordo com as experiências vivenciadas por cada pessoa, está no prazer de superar desafios. Portanto, foram abordadas as chamadas primeiras teorias motivacionais (teorias das Necessidades de Maslow, Teoria $\mathrm{X}$ e $\mathrm{Y}$, Motivação-higiene), as teorias contemporâneas de motivação (ERC, Necessidades adquiridas, Expectação, Eqüidade, Determinação de metas) e as práticas utilizadas, atualmente, para motivar pessoas nas organizações.

c) Comunicação

O momento atual está exigindo muito das pessoas, principalmente habilidades no relacionamento e capacidade nos envolvimento com as pessoas. A pessoa, ao nascer, não traz em sua bagagem genética a capacidade de se comunicar, ela aprende por meio da língua falada e escrita. Por meio da comunicação o ser humano consegue transmitir suas idéias, seus pensamentos e suas emoções. Assim, são abordadas as teorias de comunicação nas organizações de forma escrita, verbal, não-verbal, por meio eletrônico, em reuniões, por telefone.

d) Análise transacional

Esta técnica assemelha-se a uma terapia psicológica para melhorar o relacionamento interpessoal, permitindo a cada indivíduo auto-diagnosticar sua interrelação com os outros para modificá-la e melhorá-la, gradativamente. O nível de intervenção trabalhado por esta técnica é o interpessoal. Vários são os instrumentos utilizados por especialistas em AT. No entanto, são abordadas as análises estrutural e funcional, e de transações.

e) Programação neurolingüística 
Nesse tópico trabalha-se com as definições de PNL (Programação Neurolingüística), modelo de mundo, pressupostos, rapport (sintonia em comunicação), o cérebro e o processo de aprendizagem, feedback e a aplicação da PNL nas organizações. Busca-se o entendimento de como as pessoas podem desenvolver-se, compreender melhor o mundo, usar os sentidos internamente para pensar e compreender como as outras pessoas pensam, usar os estímulos para ter acesso a estados mentais criativos, pensar de forma sistêmica, resolver conflitos e se comunicar melhor no ambiente de trabalho.

\section{f) Aprendizagem}

O conhecimento que as pessoas possuem a respeito de si próprias e do ambiente onde interagem é obtido pelo processo de aprendizagem que ocorre no decorrer da vida, o qual modifica-se, permanentemente, ocasionando mudanças em seus comportamentos. A aprendizagem é definida por Robbins (1999:45) como "qualquer mudança relativamente permanente no comportamento que ocorre como resultado de experiência".

\section{g) Comportamento individual}

No comportamento individual entram em cena as teorias sobre habilidades, capacidades de percepção, tomadas de decisão, criatividade e intuição, e como aprender a conviver com pessoas de diferentes personalidades.

h) Ética no trabalho

Todo ser humano, desde o seu nascimento, tem convívio com seus semelhantes por meio de relacionamentos. Cada pessoa constrói suas crenças e valores que nortearão seus comportamentos ao longo da vida, em busca do alcance de objetivos. Desta forma, são trabalhadas as teorias e códigos de ética profissional.

i) Administração do estresse

As situações vivenciadas pelo ser humano nas organizações, como medo, excitação, confusão, perigo, e outras, causam um conjunto de reações físicas, químicas e mentais denominadas estresse. Assim são abordadas as teorias e práticas sobre 0 estresse no ambiente de trabalho.

j) Equipes de trabalho

As empresas, atualmente, estão trabalhando mais intensamente no desenvolvimento de grupos organizacionais e equipes de trabalho. São abordadas as teorias que tratam da formação e desenvolvimento de equipes de trabalho.

k) Conflito e negociação

O profissional, na organização, ao executar uma atividade, está sujeito a passar por conflitos com colegas de equipe ou grupo, clientes e fornecedores. São trabalhadas as teorias que tratam da resolução de conflitos e do processo de negociação.

Uma vez apresentadas as teorias sobre a gestão de pessoas e sobre o comportamento humano nas organizações, que dão suporte ao delineamento do modelo de formação comportamental de auditores contábeis, passa-se a apresentar a metodologia da pesquisa realizada na área de gestão de pessoas em empresas que prestam serviços de auditoria.

\section{Metodologia Da Pesquisa}

O tipo de pesquisa utilizada é a qualitativa com abordagem descritiva. $\mathrm{Na}$ abordagem descritiva faz-se o uso do recurso de estudos multicasos.

O universo deste estudo compreendeu empresas de auditoria contábil independente nacionais e internacionais, instaladas na região sudeste e sul do Brasil. Coletou-se dados de quatro empresas internacionais que estão entre as cinco maiores do mundo (as chamadas big five) e de uma nacional. As amostras foram selecionadas pelo critério de intencionalidade e acessibilidade.

Os entrevistados são profissionais que trabalham na área de gestão de pessoas, sendo uma de cada empresa pesquisada. A formação dos entrevistados é a seguinte: um 
graduado em Contabilidade, com pós-graduação em Administração e Economia; dois graduadas em Psicologia; um graduado em Pedagogia com Especialização em Psicodrama Aplicado; um graduado em Administração de Empresas e em Psicologia, com especialização em Administração para Consultores, com ênfase em Organização e Recursos Humanos.

As unidades de investigação e de análise não foram identificadas nesta pesquisa, visando preservar as empresas e os entrevistados. Assim foi utilizado na descrição e análise dos dados a denominação de empresa 1, 2, 3, 4 e 5.

\section{Descriçao e análise do estudo multicaso}

As empresas de auditoria possuem estruturas organizacionais como as demais empresas. Em suas estruturas existem os planos de carreira que estipulam a descrição dos cargos, os critérios de seleção para recrutamento de pessoal, os programas de capacitação e desenvolvimento continuado, a orientação, confirmação periódica do desempenho profissional e oportunidades de crescimento. Tais organizações possuem estruturas de cargos hierarquizados, assemelhados com os prefixos citados na literatura, apenas variando em número de cargos.

A estrutura organizacional na área de auditoria das empresas pesquisadas possui cargos hierarquizados conforme demonstrado na Figura 2.

\begin{tabular}{|c|c|c|c|c|}
\hline EMPRESA 1 & EMPRESA 2 & EMPRESA 3 & EMPRESA 4 & EMPRESA 5 \\
\hline $\begin{array}{l}\text { - Estagiário I/ } \\
\text { assistente } \\
\text { trainee } \\
\text { - Estagiário II/ } \\
\text { assistente } \\
\text { júnior } \\
\text { - Assistente } \\
\text { pleno } \\
\text { - Auditor júnior } \\
\text { - Auditor pleno } \\
\text { - Auditor sênior } \\
\text { - Supervisor } \\
\text { - Gerente } \\
\text { - Sócio }\end{array}$ & $\begin{array}{l}\text { - Assistente } \\
\text { novo } \\
\text { - Assistente } \\
\text { experiente } \\
\text { - Sênior } \\
\text { - Sênior- } \\
\text { experiente } \\
\text { - Gerente } \\
\text { - Gerente } \\
\text { experiente } \\
\text { - Diretor } \\
\text { - Sócio-diretor }\end{array}$ & $\begin{array}{l}\text { - Trainee } \\
\text { - Auditor } \\
\text { - Auditor } \\
\text { Sênior } \\
\text { - Gerente } \\
\text { - Gerente } \\
\text { Sênior } \\
\text { - Diretor } \\
\text { - Sócio }\end{array}$ & $\begin{array}{l}\text { - Trainee } \\
\text { - Assistente } \\
\text { - Semi-Sênior } \\
\text { - Supervisor } \\
\text { - Gerente } \\
\text { - gerente } \\
\text { Sênior } \\
\text { - Diretor } \\
\text { - Sócio }\end{array}$ & $\begin{array}{l}\text { - Auxiliar/ } \\
\text { estagiário } \\
\text { - Assistente C } \\
\text { - Assistente B } \\
\text { - Assistente A } \\
\text { - Sênior C } \\
\text { - Sênior B } \\
\text { - Sênior A } \\
\text { - Supervisor } \\
\text { - Gerente } \\
\text { - Sócio }\end{array}$ \\
\hline
\end{tabular}

Figura 2 - Denominações dos cargos de auditor nas empresas de auditoria pesquisadas.

Para preencher os cargos vagos nestas empresas é realizado o processo de recrutamento de estagiário/trainee/auxiliar/assistente. As empresas, por meio de palestras e feiras em universidades/faculdades, anúncios em jornais, em suas páginas disponíveis na internet e indicação por profissionais, possibilitam aos candidatos o envio de curriculum vitae para iniciar o processo de recrutamento.

Em casos especiais, em emergência, são contratados profissionais experientes em algumas destas empresas para ocupar cargos de auditor sênior ou equivalente, dependendo da estrutura organizacional de cada empresa.

Normalmente, para ocupar o cargo de estagiário/trainee/auxiliar/assistente, baseado em seus planejamentos e de acordo com a expansão dos negócios, as empresas fazem o recrutamento externo de estudantes de graduação ou recémformados. Pode ocorrer, também, o recrutamento interno, remanejando profissionais de outras áreas da empresa que tenham o perfil adequado para realizar serviços de 
auditoria. Porém, este procedimento tem pouca representação no processo de recrutamento nas empresas pesquisadas.

A quantidade de envios de curriculum vitae varia de empresa para empresa. Há uma empresa que recebeu em torno de 7.000 currículos para preencher, aproximadamente, 50 vagas. Outra recebeu, em torno de 5.000 currículos para ocupar a mesma quantidade de vagas. As demais também têm números aproximados a esta para ocupar suas vagas.

São avaliados os melhores curriculum vitae enviados, nos quais se verifica, em primeiro lugar, a formação que o candidato possui. O perfil procurado por estas empresas é o seguinte:

a) pessoas sem experiência de trabalho, que estejam na faixa etária entre 20 a 25 anos de idade;

b) estudantes dos cursos de Administração de Empresas (incluindo especialidades, tais como: Análise de Sistemas, Comércio Exterior), Ciências Contábeis, Ciências da Computação (Processamento de Dados, Tecnologia da Informação), Direito, Economia (Relações Internacionais) e Engenharia. Também os recém-formados nesses cursos fazem parte do público-alvo para o recrutamento de novos auditores.

c) sólida formação acadêmica de universidades/faculdades USP (Universidade do Estado de São Paulo), FGV (Fundação Getúlio Vargas), PUC (Pontifícia Universidade Católica), Mackenzie e FAAP (Faculdade Armando Alves Penteado). Algumas empresas também consideram o conceito da universidade, avaliado pelo 'provão' ou pelo ranking publicado na revista Playboy do mês de setembro, pela Editora Abril, sobre os cursos e universidades brasileiras;

d) inglês; e

e) conhecimentos de informática como usuário.

As empresas que contratam pessoas que não possuem a formação acadêmica em Ciências Contábeis deixam claro, desde o início do processo seletivo, a necessidade da formação em Ciências Contábeis para seguir carreira. As empresas de auditoria em São Paulo possuem convênios com a UNIP (Universidade Paulista) para formar estes profissionais em Ciências Contábeis. O curso tem duração de um ano, e é realizado de segunda a sábado.

O contratado que não é formado em Ciências Contábeis terá sua carreira limitada a auditor sênior, e não será promovido a supervisor, gerente e sócio.

No processo de seleção destas empresas são encontradas as seguintes práticas:

a) testes escritos e redação;

b) testes de conhecimentos e habilidades;

c) análise de grafologia;

d) Testes orais (apresentação de um tema);

e) dinâmica de grupo e/ou prova situacional;

f) entrevista de seleção.

Os candidatos que tiverem a melhor pontuação nestas fases são contratados. Por meio destes testes as empresas pesquisadas procuram verificar os candidatos que possuem comportamento adequado para realizar trabalhos de auditoria. É dada ênfase nas seguintes habilidades e competências:

a) gosto pelo aprendizado contínuo;

b) estudantes jovens, agressivos, talentosos e brilhantes.

c) pessoas dinâmicas, ambiciosas, com iniciativa e espírito empreendedor;

d) pessoa de negócio em longo prazo (um futuro sócio), que queira fazer carreira na empresa;

e) capacidade de trabalhar em equipe, desenvolver e passar conhecimentos e agregar valor aos clientes internos e externos da empresa; 
f) pessoa empreendedora, que busque objetivos coletivos, flexível em determinadas situações, persistente e com bom relacionamento interpessoal;

g) perfil psicológico voltado a ser investigativo e analisador;

h) liderança e boa comunicação verbal e não-verbal;

i) capacidade de persuasão, argumentação e de lidar com situações de maior pressão;

j) capacidade de resolver problemas e segurança pessoal; e

k) gosto pelo aprendizado contínuo;

Com estas habilidades e competências, já identificadas no processo seletivo, iniciase o processo de formação destes novos profissionais, que envolve tanto os conhecimentos técnicos (contabilidade, auditoria, tributário, legislação societária, normas, etc.), como os conhecimentos necessários ao comportamento compatível com a função de auditor. A capacitação de auditores nos aspectos comportamentais envolve os seguintes cursos:

a) liderança, motivação, comunicação, negociação e administração de conflitos;

b) técnicas de apresentação e de entrevista;

c) trabalho em equipe;

d) a visão do auditor, valores, missão, ética e independência;

e) qualidade no atendimento ao cliente interno e externo;

f) responsabilidade na supervisão da administração dos trabalhos e no desenvolvimento de pessoal;

g) coaching/mentoring, auto-instrução, formação de instrutores;

h) etiqueta profissional e reuniões com clientes internos e externos;

i) eficácia em comunicação oral e assertividade, em que é empregada a teoria de Análise Transacional;

j) criatividade e administração de projetos.

Esses treinamentos visam aprimorar as competências e habilidades comportamentais dos auditores. Além destes cursos as empresas incentivam a realização de cursos de pós-graduação, língua inglesa, seminários externos e palestras sobre assuntos diversos. A maioria das empresas pesquisadas pagam estes cursos para seus auditores.

Para o acompanhamento do desenvolvimento das competências técnicas e comportamentais dos auditores, as empresas utilizam-se da avaliação de desempenho. As empresas pesquisadas utilizam a metodologia tradicional de avaliação de desempenho, em que o superior avalia o subordinado. As avaliações nestas empresas são periódicas. Em três empresas pesquisadas têm-se avaliações a cada projeto de trabalho igual ou superior a 40 horas, nas outras duas têm-se duas avaliações por ano. Os indicadores encontrados no instrumento de avaliação, além dos conhecimentos de contabilidade, tributários, societários, auditoria e fluência na língua inglesa, avalia as seguintes habilidades e competências comportamentais:
a) ética profissional, independência em relação aos clientes e atuação com equilíbrio e juízo imparciais;
b) entusiasmo, compromisso com a excelência e alcance dos objetivos;
c) atendimento das expectativas do cliente;
d) construção de equipe;
e) liderança de equipe, comunicação, contatos, relações e respeito pela cultura corporativa;
f) capacidade de mudança e flexibilidade;
g) capacidade de negociação, apoio e delegação;
h) gestão de projetos, qualidade e administração do risco.
i) pensamento conceitual e comprometimento com o auto-desenvolvimento;
j) enfoque direcionado ao network, conhecimento dos negócios e sua aplicação; 
k) compromisso com o negócio e desenvolvimento da prática;

l) capacidade de pensamento crítico, auto-confiança, argumentação e orientação para resultados;

m) habilidade de comunicação verbal e escrita;

n) maturidade, responsabilidade, habilidades interpessoais e motivação/orientação para o desenvolvimento pessoal/profissional;

o) gestão de pessoas (coaching/mentoring, relacionamento com equipe/clientes, técnicas de negociação e entrevistas);

p) eficácia pessoal, aprendizagem contínua, lealdade;

q) capacidade de conciliar interesses pessoais com os da empresa;

r) capacidade de prestar serviços de qualidade para os clientes internos e externos;

s) aparência e comportamento profissional.

A avaliação de desempenho serve, também, para promover, identificar carências de capacitação e desligar auditores de seus quadros. Auditores que recebem avaliações de desempenho excelentes podem ser promovidos antes do tempo mínimo estabelecido no plano de crescimento na carreira da empresa. Também as baixas avaliações não permitem que o auditor seja promovido, é dado feedback sobre a performance e existe um acompanhamento especial junto a esse profissional.

Para chegar até o cargo de gerente de equipe de auditoria, depende da avaliação de desempenho. Para se tornar um sócio, além da avaliação de desempenho, é necessária a abertura de uma vaga de sócio. Esta vaga pode ser oriunda de aposentadoria, expansão da empresa, e outros. Em uma das empresas pesquisadas o auditor tem a possibilidade de chegar a sócio e permanecer como sócio participante somente até os 60 anos de idade. Ao completar 60 anos de idade, pára de trabalhar e pode fazer retiradas de valores. Isto possibilita que novas pessoas possam ascender na empresa, permitindo a renovação.

\section{Modelo de formação comportamental}

Há muito tempo a contabilidade vem utilizando modelos para representar de forma simplificada dados e informações por meio das demonstrações contábeis. Para Beuren (2000:17), "desenvolver o conhecimento, muitas vezes, implica trabalhar com abstrações da natureza". Tais abstrações podem representar modelos. Desta forma, "um modelo representa ou descreve os elementos relevantes de um processo ou de uma situação e as interações existentes entre eles". Assim, um modelo abstraído de uma realidade, facilita o entendimento e manipula as relações ocorridas entre variáveis que integram um universo, sistema ou processo. Existem, também, diversos modelos que são utilizados por pessoas e organizações, conforme apresentado na Figura 3.

\begin{tabular}{|l|l|}
\hline \multicolumn{1}{|c|}{ MODELO } & \multicolumn{1}{c|}{ FINALIDADE } \\
\hline Modelo de decisão & Identifica o curso de eventos futuros \\
\hline $\begin{array}{l}\text { Modelo de } \\
\text { mensuração }\end{array}$ & Dá suporte aos modelos decisórios \\
\hline $\begin{array}{l}\text { Modelo de } \\
\text { informação }\end{array}$ & Dá suporte aos modelos de decisão e mensuração \\
\hline Modelo de gestão & $\begin{array}{l}\text { É uma representação teórica do processo de administrar uma } \\
\text { entidade, a fim de garantir a consecução da missão para a qual } \\
\text { foi concebida }\end{array}$ \\
\hline
\end{tabular}

\section{Figura 3 : Modelos e suas finalidades}

Fonte: Adaptado de Beuren (2000)

Os modelos apresentam vantagens e desvantagens aos seus usuários. Beuren (2000:18) explica que "um modelo caracteriza-se como uma importante ferramenta para 
conceber algo e representar, simular ou idealizar essa realidade por meio de objetos, fluxos, idéias ou palavras, pois ele sumariza os efeitos e relacionamentos mais relevantes de determinada situação ou problema específico".

Desta forma, por meio da pesquisa em literaturas que fornecem suporte conceitual e pelo trabalho de campo, buscou-se elementos para delinear um modelo que represente a realidade de um determinado universo em um espaço de tempo. Na Figura 4 apresentase o delineamento desse modelo de formação comportamental de auditores contábeis independentes.

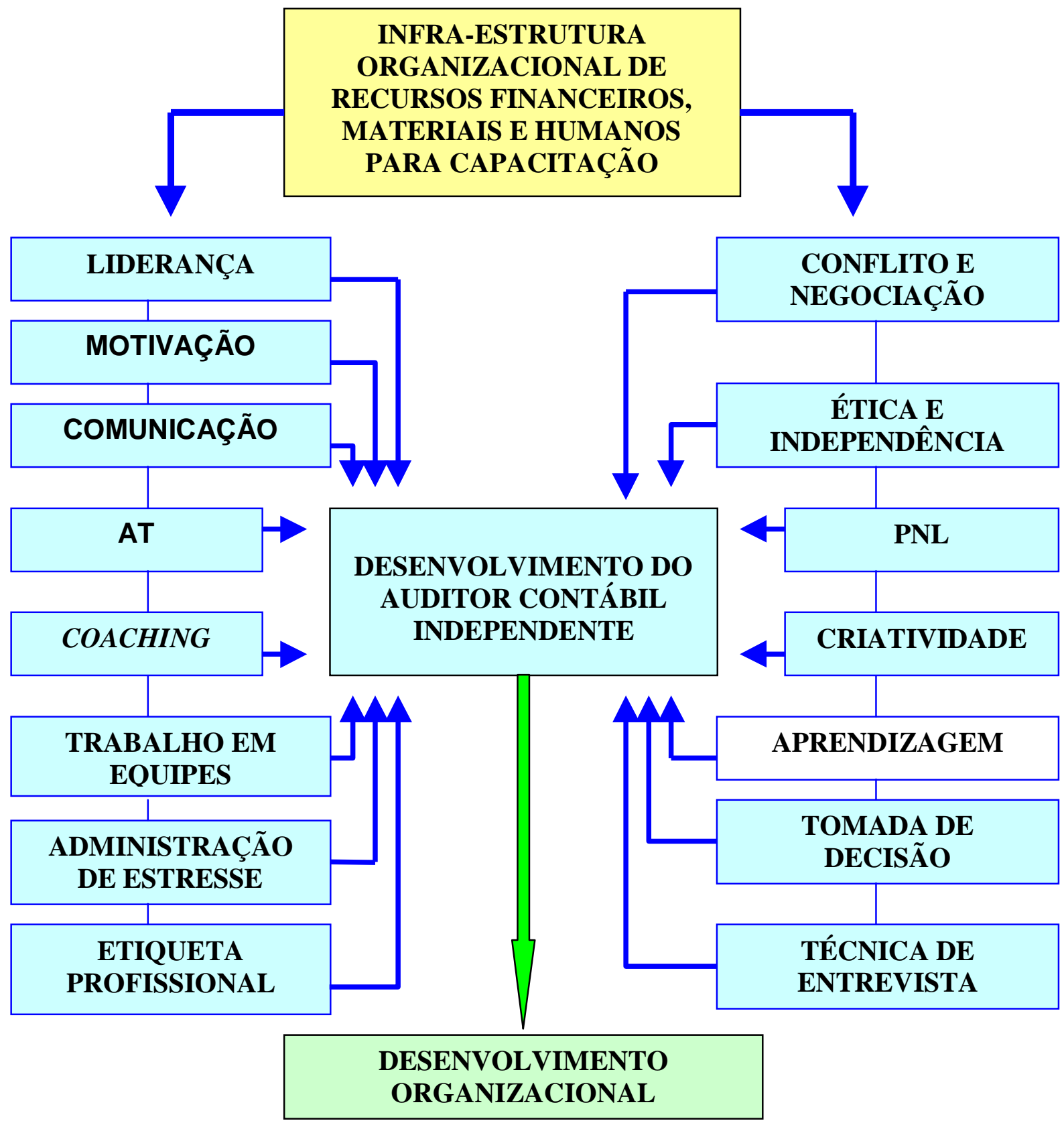

Figura 4 : Modelo de formação comportamental de auditor contábil independente

A organização de auditoria, capacitando seus profissionais nos itens elencados na Figura 4, estará investindo em seu desenvolvimento. O modelo de formação de auditores contábeis independentes, com ênfase na abordagem comportamental apresentado é detalhado, evidenciando a contribuição que cada capacitação poderá trazer ao auditor na realização de seu mister, iniciando pela liderança. 


\section{Liderança}

Como os auditores contratados já possuem potenciais de liderança, identificados no processo seletivo, os quais indicam chances de se tornarem líderes de sucesso, a empresa de auditoria pode capacitar seus novos profissionais nos conceitos, teorias e práticas de liderança. A auditoria é uma atividade que exige a capacidade de liderança e deve ser executada sob a responsabilidade de um líder.

O auditor, conhecendo suas características de liderança e quais são as formas de desenvolvê-las, poderá se autodesenvolver e ter desempenhos eficientes nas atividades de auditoria.

Adicionalmente, o auditor precisa auxiliar no desenvolvimento dos membros que compõem a equipe de auditores, bem como auxiliar no desenvolvimento dos processos do auditado, apresentando recomendações e sugestões de melhorias. Uma das características do líder eficiente é auxiliar seus liderados a obterem sucesso em suas atividades. Isto inclui tanto os auditores subordinados, como os profissionais da entidade auditada.

O processo de liderança adotado pelos líderes determina, na maioria das vezes, que os objetivos estabelecidos sejam alcançados e, para isto, o auditor precisa querer e saber liderar as outras pessoas, utilizando as teorias, práticas e estilos de liderança existentes.

O auditor pode, também, utilizar o estilo de liderança mais apropriado, no relacionamento com as pessoas de contato da entidade auditada, para coletar as evidências de auditoria. $O$ processo de coleta de evidências por meio de entrevistas é um recurso essencial de liderança. Portanto, cabe ao auditor conhecer as teorias e os melhores estilos de lideranças existentes.

Assim, presume-se que as teorias de liderança são fundamentais para o desempenho dos auditores contábeis independentes na realização das auditorias. 0 auditor conhecendo as teorias de liderança existente saberá como melhor tirar proveito de uma auditoria, pois ele encontrará pessoas de todos os tipos e culturas nas organizações. Quanto mais o auditor conhecer e dominar as teorias de liderança melhor ele poderá ajustar o estilo de liderança na hora de coletar as evidências, fazer a abertura e o encerramento de reuniões de apresentação dos relatórios de auditoria, resolver conflitos, negociar, tomar decisões, atuar como instrutor/aconselhador, apoiando e motivando as pessoas de contato.

\section{Motivação}

No processo auditorial, o auditor depara-se com situações críticas que podem ocasionar perda de sua motivação, bem como desmotivar as pessoas de contato. A motivação é a energia, força e impulso interno, que movem as pessoas na busca de determinado objetivo. Desta forma, para manter o nível de motivação entre os auditores e auditados, poderão dar atenção aos seguintes itens:

- estimular o emprego de esforços para atingir as metas traçadas pela organização, no cumprimento dos prazos previstos nos trabalhos de auditoria;

- incentivar desafios e assumir responsabilidades nos trabalhos de campo;

- estimular a automotivação e a auto-direção;

- incentivar a criatividade na resolução de problemas e na prevenção dos mesmos;

- reconhecer em público resultados positivos na realização de um trabalho de auditoria;

- incentivar a progressão na carreira de auditor;

- dar exemplo e manter boas relações interpessoais;

- propiciar boas condições de trabalho e incentivos na remuneração;

- incentivar o desenvolvimento profissional e pessoal; 
- propiciar capacitação;

- dar tratamento igual às pessoas de mesmo nível hierárquico;

- dar feedback às pessoas sobre seus desempenhos;

- estimular a participação do planejamento das atividades;

- incentivar a tomada de decisão nas atividades do dia-a-dia;

- estimular a participação nas atividades em equipe;

- ouvir as opiniões das pessoas;

- manter as pessoas informadas sobre os acontecimentos da empresa;

- dar mais autonomia na realização dos trabalhos;

- demonstrar postura ética aos auditores e auditados;

- estimular a compreensão do comportamento das outras pessoas;

- estimular a conciliação entre a vida profissional e a familiar;

- propiciar segurança e saúde no trabalho;

- considerar os interesses individuais e os da equipe de auditoria;

- estimular as pessoas a assumirem riscos;

- estimular a auto-gestão; e

- criar canais de comunicação eficientes.

Com o conhecimento das teorias motivacionais, o auditor poderá compreender melhor as forças que auxiliam no seu desenvolvimento interior, de cada membro da equipe e dos auditados, bem como compreender o porquê de as pessoas agirem de formas diferentes em determinadas situações. Por meio do exemplo, da fala, das recomendações e elogios em relatórios de auditoria, o auditor poderá motivar as pessoas de contato, bem como criar um ambiente agradável para a equipe de auditores no trabalho de campo, a fim de que possam sentir-se motivados e empregar suas energias na execução de serviços com alta qualidade.

\section{Comunicação}

De posse dos conhecimentos acerca das teorias e técnicas de comunicação entre pessoas e o processo de comunicação dentro das organizações, o auditor poderá interagir melhor com seus colegas de equipe de auditoria, e com as pessoas de contato nas entidades auditadas.

O auditor deve ter a capacidade de transportar por meio de palavras suas idéias, conhecimentos, pensamentos e emoções, tanto de forma escrita, como verbal e nãoverbal entre auditores e auditados. Assim, o auditor precisa saber se comunicar pela palavra escrita, falada e linguagem do corpo na condução de reuniões e no repasse de informações. Também deve saber se comunicar pelo telefone e correio eletrônico.

\section{Análise transacional - AT}

Para auxiliar no equilíbrio interno quando da realização dos trabalhos de auditoria, o auditor pode utilizar-se da análise transacional. O auditor, conhecendo a teoria de análise transacional, poderá interagir melhor com seus colegas de trabalho, clientes e fornecedores, pois no processo de comunicação não é possível prever a reação das pessoas, em resposta a uma intervenção administrativa.

A situação entre o auditor e auditado, bem como entre os membros da equipe de auditoria, leva a uma reflexão sobre até que ponto os comportamentos, pontos de vista e reações humanas podem influenciar no resultado de uma auditoria. Quando do contato das pessoas umas com as outras é comum observar divergência de comportamento. Portanto, cabe ao auditor conhecer os estados do eu que residem em cada pessoa para tirar o melhor proveito nas transações relacionadas ao processo auditorial, seja em reuniões, na resolução de problemas, conflitos, tomada de decisões, negociação e no repasse de instruções. 
Assim, o auditor, reconhecendo os estados do eu, pode influenciar positivamente as transações entre auditores/auditores, auditores/fornecedores e auditores/auditados.

No processo de coleta de evidências, por meio da entrevista de auditoria, é possível identificar os motivos ocultos ou involuntários dos auditados. Assim, o auditor poderá interagir na entrevista de auditoria, por meio da análise dos estados do eu do auditado, para reagir da forma mais adequada e alcançar o objetivo da auditoria.

$\mathrm{O}$ auditor pode utilizar-se das análises das transações quando precisa influenciar diretamente nos processos de entrevista de coleta de evidências de auditoria, principalmente, quando há um comportamento contínuo de justificação do auditado, ele pode interrompê-la, cruzando-a e continuando num outro nível.

\section{Programação neurolingüística - PNL}

Com a utilização da PNL, o auditor pode se auto-conhecer, aumentando sua confiança e segurança, bem como auxiliar os membros da equipe de auditoria no progresso pessoal e profissional.

O auditor, ao adquirir o conhecimento da PNL, poderá substituir padrões limitadores de sua vida, como dificuldades de comunicação, expectativas, conflitos e outros comportamentos indesejáveis, por padrões facilitadores que possibilitem mudanças de atitudes, motivação, empatia, comunicação, liderança, trabalho em equipe, autoconfiança, pensamento sistêmico, capacidade de influenciar, administrar pressões e conflitos, tomar decisões, melhorar o desempenho, o aprendizado e a criatividade, facilidade para encontrar soluções e estabelecer objetivos.

No processo de comunicação, o auditor pode confirmar aquilo que fala por meio de suas expressões não-verbais, para ajudar a convencer a pessoa de contato. Isso ajuda criar convicção, mostrar verdade, sinceridade e ajudar a pessoa de contato no processo de aprendizagem.

\section{Coaching/mentoring (instrutor)}

Os auditores, além de executar suas atividades de auditoria, precisam ter a competência de repassar conhecimentos a outro auditor, equipes de auditores e para auditados. Isso exige a formação de instrutor, a qual requer capacitação em teorias de aprendizagem, liderança, motivação, boa comunicação, criatividade, iniciativa, autoconhecimento e auto-aprendizado.

\section{Técnica de entrevista}

O processo de coleta de entrevista, por meio da técnica de entrevista, exige do auditor capacidades de elaboração de perguntas, para que o auditado possa discorrer sobre suas atividades. A prática tem demonstrado que a maior parte das informações existentes em uma organização não fica armazenada em sistemas e documentos, e sim, na memória das pessoas que fazem parte da organização.

Para isto o auditor precisa formular perguntas abertas que possibilitam ao auditado dar várias respostas, e que sejam referentes à disposição adquada das atividades, ao entendimento dos processos, à execução correta e em relação à eficácia das atividades.

$\mathrm{O}$ auditor deve conduzir as perguntas de auditoria como se fosse um bate papo, ou uma conversa informal. Deve tomar cuidado para não fazer perguntas mal formuladas ou um comentário que gere interpretações diversas, pois podem causar mudanças na postura do auditado.

Nesta técnica são exigidos do auditor a capacidade de ouvir atentamente, de passar feedback, de negociar, de tomar decisão, liderar, comunicar, motivar, ter ética e independência, ter criatividade, ser instrutor e conhecer um pouco de análise transacional e de programação neurolingüística. Isso vai ajudá-lo na obtenção das evidências 
necessárias que darão suporte às outras técnicas de coletas de evidências no processo auditorial.

\section{Aprendizagem}

O processo de auditoria, pela vivência em trabalhos diversificados e com pessoas de diferentes culturas, permite que os auditores tenham aprendizados constantes, porém, torna-se necessário capacitá-los nos conceitos e nas técnicas de aprendizagem, principalmente, no auxílio da capacitação de formação de instrutores/coaching/mentoring.

Portanto, é importante que 0 auditor conheça as teorias de aprendizagem enfocando os seguintes itens:

- motivação para aprendizagem;

- criação do clima de aprendizagem;

- expressão verbal e não-verbal (técnicas de comunicação com o auxílio de AT e PNL) no processo de repasse de instruções;

- auto-controle e administração de situações críticas no processo de formação;

- conhecimento das disciplinas da aprendizagem organizacional.

Assim, o auditor pode ajudar no desenvolvimento dos colegas de equipe e dos auditados, bem como auto-desenvolver-se, melhorando suas habilidades, a criatividade e a capacidade de percepção.

\section{Etiqueta profissional}

Um auditor contábil independente precisa ter habilidades para executar os processos de auditoria; para ter bons relacionamentos com as outras pessoas, compreendendo os sentimentos delas; e para identificar problemas do auditado, sugerindo e recomendando melhorias.

Além dessas habilidades, também são requeridas, ao auditor, habilidades para se relacionar socialmente. Estas habilidades dizem respeito à capacidade de causar uma boa imagem aos auditados, quais comportamentos deve ter e quais assuntos devem ser tratados em eventos, procurando sempre ser simpático, ter atitudes positivas, e preservar os valores e a ética profissional.

\section{Ética profissional e independência}

Assim como nos eventos sociais, o auditor no ambiente de trabalho precisa ter comportamentos éticos, deve seguir as normas éticas da profissão de auditor contábil independente, mantendo sempre a imparcialidade em suas ações para preservar a independência em seus julgamentos. Desta forma, é preciso capacitá-lo para tal, dentro dos valores e ética da empresa de auditoria, ou seja, é preciso passar aos auditores quais são os valores que a empresa possui.

\section{Criatividade}

Muitas vezes no processo auditorial, tanto entre auditores/auditores, como entre auditores/auditados, encontram-se fases difíceis de serem vencidas, as quais requerem do auditor a capacidade de criar alternativas ou soluções, principalmente, quando se trabalha com pessoas desconhecidas e processos empresariais ainda nunca vistos. Isso exige habilidades para apresentar novas formas de realizar um processo, de interpretar legislação, normas, procedimentos e práticas de controle de gestão.

\section{Tomada de decisão}

Nos impasses encontrados no dia-a-dia da profissão, o auditor precisa tomar decisões. Tais impasses podem ocorrer no relacionamento entre a equipe de auditores, como no relacionamento entre auditores e auditados, em cima de fatos, processos ou práticas que estão sendo adotados pela entidade auditada. Para tanto, o auditor necessita 
conhecer as fases e as técnicas que podem ser adotadas no processo de tomada de decisão, principalmente em processos que geram grandes incertezas.

\section{Trabalho em equipe}

O trabalho do auditor contábil independente é realizado em equipes de três ou mais auditores que se deslocam à entidade auditada. O processo de auditoria engloba as reuniões iniciais e finais, a coleta de evidências das transações, do sistema contábil e de controles internos, o qual exige dos auditores capacidade de se relacionar, de cooperar, de motivar, de liderar, de comunicar, de auxiliar, de resolver problemas internos e do auditado.

Assim, o auditor deve conhecer quais os tipos de habilidades, personalidades, as formas de aprendizagem, os processos de percepção, as tomadas de decisões, os conflitos e formas de negociação, e a satisfação no trabalho que permeiam os membros dos grupos e equipes de auditoria, bem como nas organizações auditada.

\section{Conflito e negociação}

$O$ auditor deve conhecer os tipos de conflitos e as formas de negociação. É importante que o auditor saiba como lidar com os conflitos dentro da equipe de auditoria e, principalmente, entre auditor e auditados. Muitas vezes a coleta de evidências pode gerar o conflito, o que requer do auditor ou da equipe de auditoria habilidades de negociação.

Outro momento que pode gerar conflito são as reuniões para apresentar o resultado da auditoria. Entra em cena a capacidade do auditor de negociar e conduzir esses conflitos, para que sejam construtivos e agreguem valor à entidade auditada e à equipe de auditores. Muitas empresas, departamentos ou setores possuem visão distorcida dos trabalhos da auditoria, o qual ocasiona resistência no repasse de informações e na negociação. Apesar de o auditor contábil independente possuir determinada autoridade no processo auditorial, deve evitar utilizá-la, pois ela traz resultados parciais e de curto prazo, muitas vezes, fechando as portas ao auditor.

Portanto, isso requer o conhecimento de técnicas de negociação, em que auditores e auditados saiam ganhando. É importante que, em todo o processo da negociação, os auditores utilizam-se da 'lupa', enfatizando os pontos positivos encontrados no auditado. Isto ajuda a minimizar o efeito do medo nos trabalhos de auditoria e possibilita a criação de um clima favorável a uma boa negociação.

\section{Estresse no trabalho}

O auditor no processo de coleta de evidências enfrenta situações conflitantes com os auditados, com os membros da própria equipe de auditoria e com a empresa de auditoria, com a legislação aplicável às empresas, e, principalmente, em função do maior número de horas trabalhadas na realização de auditorias ocorrer nos meses de janeiro a março de cada ano. Esses fatores podem causar estresse no auditor, portanto, ele precisa estar capacitado para conhecer as fontes potenciais de estresse existentes no seu ambiente de trabalho e quais suas conseqüências. Tanto o auditor como a empresa de auditoria devem monitorar e dar atenção especial a essas fontes de estresse, para que elas se tornem o chamado eustresse, que estimula a criatividade, o esforço e o melhor desempenho do auditor em suas atividades.

Desta forma, mantendo um nível moderado de estresse no ambiente de trabalho, estimula os auditores na busca da satisfação de suas necessidades na área profissional, pessoal e social, bem como propicia uma qualidade de vida no trabalho, o qual permite que a inovação e a criatividade sejam estimuladas. 


\section{Conclusão}

O principal produto de uma empresa de auditoria contábil independente é o conhecimento que seu quadro de pessoal possui. As estruturas organizacionais destas empresas pesquisadas permitem que os auditores tenham valor relativo e valor absoluto no desempenho de suas funções nos cargos, pois a empresa possui uma seqüência ou disposição hierárquica estabelecida. Isto propicia ao auditor, desde seu ingresso, possibilidades de crescimento na organização e ajuda a mantê-lo motivado para o trabalho, permitindo que ele se torne um sócio da empresa.

As empresas procuram valorizar as competências dos seus profissionais, a partir do momento em que definem o conhecimento, habilidades e capacidades necessários ao desempenho eficiente e eficaz nos cargos de auditor. Os recrutadores e selecionadores mostram no processo seletivo as perspectivas futuras da profissão de auditor, a possibilidade de absorção de muito conhecimento em pouco tempo de trabalho, bem como as dificuldades inerentes à profissão de auditor.

No processo de recrutamento e seleção são empregadas as técnicas recomendadas na literatura, que permitem que sejam identificadas as pessoas que possuem comportamento adequado para realizar trabalhos de auditoria.

Uma vez contratados novos auditores com perfil desejado, as empresas investem em suas capacitações, tanto na área técnica, como na comportamental. Pois a qualidade dos serviços prestados por seus auditores é o que determina a competitividade dessas empresas no mercado. Quanto mais qualificado for um auditor, melhor tende a ser a qualidade de seu serviço.

Para aferir as competências e habilidades de seus profissionais, as empresas utilizam instrumentos de avaliação de desempenho. Por meio da avaliação, as empresas de auditoria procuram gerir seu quadro de pessoal, permitindo que o profissionalismo seja atingido no campo da auditoria.

A gestão de pessoas nas empresas pesquisadas acompanha a evolução do mercado de trabalho. Isso possibilita ter profissionais habilitados e com competências necessárias para enfrentar as mudanças rápidas e radicais do ambiente globalizado.

A formação do auditor contábil independente, com ênfase na abordagem comportamental apresentada, poderá trazer contribuições aos processos de auditoria no estudo e avaliação dos sistemas contábeis e controles internos, no estudo dos riscos de auditoria, na aplicação das técnicas de auditorias, na coleta de evidências, nos processos de negociação e tomadas de decisões, na apresentação dos relatórios de auditoria, no atendimento de normas de auditoria, e, principalmente, na qualidade dos serviços prestados.

O tema formação comportamental de profissionais, que desenvolvem atividades que demandam controle emocional no contato junto a outras pessoas, vem a cada dia que passa recebendo maior atenção por parte dos responsáveis pela gestão de pessoas nas organizações.

\section{Bibliografia}

ALMEIDA, Marcelo Cavalcanti. Auditoria. São Paulo : Atlas, 1996.

BASSANESI, Consuelo e ZANUZZI, Fernanda. Inteligência Prática.Quem precisa de QI? Revista Amanhã: Economia e Negócios. Porto Alegre, 2000, ago, 32-35.

BERNARDI, Maria Amalia. As melhores empresas para você trabalhar. In: GUIA EXAME98. São Paulo, parte integrante da edição 669 de EXAME. Ago/1998.

BEUREN, Ilse Maria. Gerenciamento da informação. São Paulo : Atlas, 2000. CARVALHO, Antonio Vieira de e NASCIMENTO, Luiz Paulo do. Administração de recursos humanos. São Paulo : Pioneira, 2000.

CHIAVENATO, Idalberto. Gerenciando pessoas. São Paulo : Makron Books, 1997. Gestão de pessoas. Rio de Janeiro : Campus, 1999. 
FIGUEIREDO, José Carlos. O Ativo humano na era da globalização. São Paulo : Negócios, 1999.

A Era da Comunicação humana nas organizações. Palestra em Videoconferência DTCOM/CRC-SC, Julho de 2001.

FRANÇA, Edson e MOTTA, Fátima. Desenvolvendo equipes de alta performance. Palestra em Videoconferência DTCOM/CRC-SC, Julho de 2001.

GIL, Antônio Carlos. Gestão de pessoas. São Paulo : Atlas, 2001.

GOLEMAN, Daniel. Inteligência emocional. Rio de Janeiro : Objetiva, 1995.

GREEN, Paul C. Desenvolvendo competências consistentes. Rio de Janeiro : Qualitymark, 2000.

HINDLE, Tim. Como fazer entrevistas. São Paulo : Publifolha, 1999.

KANAANE, Roberto. Comportamento humano nas organizações. São Paulo: Atlas, 1999.

KRAUSZ, Rosa R. Análise transacional e trabalhabilidade. Artigo disponível no site http://www.unat.com.br/artigos/index.htm. Acesso em 14 de Março de 2001.

ROBBINS, Stephen P. Comportamento organizacional. Rio de Janeiro : LTC, 1999.

WOOD Jr., Thomas e PICARELLI FILHO, Vicente. Remuneração por habilidades e por competências. São Paulo : Atlas, 1999. 